\title{
Modeled global effects of airborne desert dust on air quality and premature mortality
}

\author{
D. Giannadaki ${ }^{1}$, A. Pozzer ${ }^{2}$, and J. Lelieveld ${ }^{1,2}$ \\ ${ }^{1}$ The Cyprus Institute, P.O. Box 27456, 1645 Nicosia, Cyprus \\ ${ }^{2}$ Max Planck Institute for Chemistry, Hahn-Meitnerweg 1, 55128 Mainz, Germany \\ Correspondence to: D. Giannadaki (d.giannadaki@cyi.ac.cy)
}

Received: 19 July 2013 - Published in Atmos. Chem. Phys. Discuss.: 11 September 2013

Revised: 14 November 2013 - Accepted: 9 December 2013 - Published: 27 January 2014

\begin{abstract}
Fine particulate matter is one of the most important factors contributing to air pollution. Epidemiological studies have related increased levels of atmospheric particulate matter to premature human mortality caused by cardiopulmonary disease and lung cancer. However, a limited number of investigations have focused on the contribution of airborne desert dust particles. Here we assess the effects of dust particles with an aerodynamic diameter smaller than $2.5 \mu \mathrm{m}\left(\mathrm{DU}_{2.5}\right)$ on human mortality for the year 2005. We used the EMAC atmospheric-chemistry general circulation model at high resolution to simulate global atmospheric dust concentrations. We applied a health impact function to estimate premature mortality for the global population of $30 \mathrm{yr}$ and older, using parameters from epidemiological studies. We estimate a global cardiopulmonary mortality of about 402000 in 2005. The associated years of life lost are about 3.47 million per year. We estimate the global fraction of the cardiopulmonary deaths caused by atmospheric desert dust to be about $1.8 \%$, though in the 20 countries most affected by dust this is much higher, about $15-50 \%$. These countries are primarily found in the so-called "dust belt" from North Africa across the Middle East and South Asia to East Asia
\end{abstract}

\section{Introduction}

Increased levels of fine particles in the air from anthropogenic and natural origin show that air quality has decreased on regional and global scales (Akimoto, 2003; Gerasopoulos et al., 2006; IPCC, 2007; Anenberg et al., 2010; Van Donkelaar et al., 2010; EEA, 2012). A large number of epidemiological investigations, including long-term cohort and time-series short-term studies, have demonstrated that atmospheric particulate matter (PM) pollution causes morbidity and premature mortality. The long-term exposure to fine particulate matter with an aerodynamic diameter smaller than $2.5 \mu \mathrm{m}\left(\mathrm{PM}_{2.5}\right)$ is associated with adverse health impacts including an increased risk of premature mortality by cardiopulmonary disease and lung cancer (Cohen et al., 2005; Krewski et al., 2009; Pope et al., 2009; Lepeule et al., 2012; Lim et al., 2012).

Because of their small size $\mathrm{PM}_{2.5}$ particles can penetrate the deep parts of the lungs and the smallest ones even the alveoli, the gas exchange cavities of the lungs. The fine $\mathrm{PM}_{2.5}$ particles can lead to cardiopulmonary and lung cancer health risks and premature mortality. Most of the studies that relate air quality and human health have been performed in urban areas, mainly in United States and Europe, where the particulate pollution is dominated by anthropogenic particles (such as PM by combustion engines). Relatively little work has been devoted to the impact of natural $\mathrm{PM}_{2.5}$ such as mineral dust. In the atmosphere large amounts of desert dust can travel thousands kilometers from their sources, which represents one of the main natural contributions to airborne PM (Kojima et al., 2006; Mahowald et al., 2010; Ginoux et al., 2012).

In many regions the levels of $\mathrm{PM}_{2.5}$ exceed by far the World Health Organization (WHO) limit $\left(10 \mu \mathrm{g} \mathrm{m}^{-3}\right)$ and the European Standard on Ambient Air Quality and Cleaner Air for Europe $\left(20 \mu \mathrm{g} \mathrm{m}^{-3}\right.$, Directive 2008/50/EC) due to regular dust events. North Africa and the Middle East are the main dust sources (over $60 \%$ of the global dust load), and therefore the potential risk to health is higher for populations in these regions. South and East Asia, with high population 
densities, are also affected by severe dust events. Unfortunately, in these parts of the world epidemiological studies and adequate air quality data are largely lacking. Several studies mention adverse health effects of the cardiorespiratory system that are associated with dust, but very few present quantitative results (De Longueville et al., 2010, 2013). These studies mainly examine short-term health effects based on timeseries analysis. To our knowledge, no studies state a clear association of desert dust particles with lung cancer. The global burden of disease (GBD) assessment for 2010 includes desert dust as part of $\mathrm{PM}_{2.5}$ pollution though did not define the dust related mortality explicitly (Lim et al., 2012).

The aim of this work is to investigate the impact of natural dust to human health and specifically to premature mortality by cardiopulmonary diseases. We assess the effect of the long-term exposure to airborne desert dust particles with an aerodynamic diameter smaller than $2.5 \mu \mathrm{m}\left(\mathrm{DU}_{2.5}\right)$ on human mortality for the year 2005 in the 231 countries distinguished by the United Nations. We also estimate the associated annual years of life lost (YLL). We use a highresolution global atmospheric chemistry-climate general circulation model to simulate global atmospheric dust concentrations. Subsequently, we apply a health impact function to estimate premature mortality for the global population of $30 \mathrm{yr}$ and older in 2005. We use epidemiological parameters from cohort epidemiological studies. We follow the same methodology as Lelieveld et al. (2013) who applied the same model and health impact function to assess the premature mortality caused by anthropogenic $\mathrm{PM}_{2.5}$ and $\mathrm{O}_{3}$ pollution for the global population of $30 \mathrm{yr}$ and older in the same period. In the following section we present the methodology and the data we used for this analysis.

\section{Methodology}

We use the following human health impact function to estimate the global annual premature mortality due to airborne desert dust $\left(\mathrm{DU}_{2.5}\right)$ (Anenberg et al., 2010; Lelieveld et al., 2013). This health impact function relates changes in pollutant concentrations to changes in mortality:

$\Delta$ Mort $=y_{0}\left(1-e^{-\beta \Delta X}\right)$ Pop,

where $\Delta$ Mort is the change in annual mortality due to a pollutant (in our study airborne desert dust), $y_{0}$ the baseline mortality rate (BMR) for a given population, $\beta$ the concentration-response function (CRF), $\Delta X$ the change in concentration of a given pollutant $X$ relative to clean conditions, and Pop the total population with an age of $30 \mathrm{yr}$ and older exposed to the pollutant. This age category coincides with the epidemiological studies in which the CRFs for different causes of mortality have been derived.

BMR data describe the number of deaths in a particular year for the population under consideration. These data were obtained from the World Health Organization (WHO) Statis- tical Information System on the country-level (WHO, 2012), based on the International Classification of Diseases 10th Revision (ICD-10) classification system. The range of ICD-10 codes used in this study for cardiopulmonary mortality is I00-I99, J00-J99, and for lung cancer mortality is C33-C34. For the countries for which the WHO does not provide national mortality data for the specific year and the relevant diseases, the appropriate WHO sub-regional level BMR data were used for each country (the global burden of disease: 2004 update, WHO, 2008). Country level data were used for 36 countries and regional data were assigned to 195 countries (in total 231 countries as documented by the United Nations and CIESIN). The assigning of sub-regional data to country level BMR does not lead to significant uncertainty in the analysis. The calculated $\Delta$ Mort scales linearly with the BMR so that countries and regions with relatively high baseline mortality rates have proportionally higher excess mortality due to air pollution.

The CRF describes the increased risk of a population to certain diseases when exposed to a particular pollutant. In this study, we assume that mortality is linearly related to concentration. The CRF is given then by the following function:

$R R=e^{\beta \Delta X}$.

We used the $R R$ s from the epidemiological study by Krewski et al. (2009) to derive the CRFs for DU 2.5 . Krewski et al. (2009) used data from the American Cancer Society (ACS) Cancer Prevention Study II (CPS-II) cohort, which included participants who were at least $30 \mathrm{yr}$ in age at the time of enrollment. For detailed information about the CRFs used in this study we refer to Krewski et al. (2009), as discussed by Lelieveld et al. (2013). According to this cohort study, a $10 \mu \mathrm{g} \mathrm{m}^{-3}$ increase in the concentration of $\mathrm{PM}_{2.5}$ is associated with an increase of $12.9 \%$ (95\% confidence interval (CI): 9.5-16.4\%) in cardiopulmonary (CPD) and $13.7 \%$ (95\% CI: 5.6-22.5\%) in lung cancer mortality. Thus, the mortality risk for cardiopulmonary disease (CPD) is $R R=1.129$, giving a $\mathrm{CRF}=0.012133$. The mortality risk for lung cancer is $R R=1.137$ and yields a $C R F=0.012839$. In Sect. 4 we discuss a sensitivity case based on a different assumption about the shape of the CRF by applying a log-linear function.

Because of the lack of epidemiological studies about the impact on premature mortality due to the long-term exposure to desert dust, the concentration-response functions applied here have been based on epidemiological cohort studies by the ACS, which may not be representative for all other countries. For regions that are strongly affected by desert dust particulates and also have different living conditions compared to the USA, like in many African, Middle East and Asian regions (with high baseline mortality rates), the ACS results are likely to be less representative (Cohen et al., 2005). In addition, although ACS cohort and other epidemiological studies 
associate exposure to ambient $\mathrm{PM}_{2.5}$ with lung cancer mortality, there is no clear evidence of a link between desert dust pollution and lung cancer risks. Similarly as the GBD assessment (Lim et al., 2012), we assume that $\mathrm{DU}_{2.5}$ affects human health the same way as $\mathrm{PM}_{2.5}$ in the ACS cohort study and therefore we implicitly assume that particle size and mass concentration matters more than their composition.

The concentrations of dust $\left(\mathrm{DU}_{2.5}\right)$ we used in our calculations for the year 2005 were obtained by Pozzer et al. (2012a, b) applying the EMAC atmospheric chemistry-climate general circulation model (Jöckel et al., 2006; Pringle et al., 2010; de Meij et al., 2012; Astitha et al., 2012). We assumed, for the global background, a dust concentration of $7.5 \mu \mathrm{g} \mathrm{m}^{-3}$ below which no premature mortality occurs (Cohen et al., 2005; Ezzati et al., 2002). Our main analysis is based on this $7.5 \mu \mathrm{g} \mathrm{m}^{-3}$ background concentration, although there are studies that indicate health impacts even at lower concentrations. In Sect. 4 we will discuss sensitivity calculations for which different background concentrations are used.

The model has a horizontal resolution of about $1.1^{\circ} \times 1.1^{\circ}$ ( $\sim 100 \mathrm{~km}$ latitude and $100 \mathrm{~km}$ longitude near the equator), and a vertical resolution of 31 levels up to the lower stratosphere. Near-surface concentrations were used for this study, i.e., being the average in the lowest model level extending over about $60 \mathrm{~m}$. We used 2005 median dust $\mathrm{DU}_{2.5}$ concentrations due to the episodic nature of desert dust outbreaks, transport and deposition, and the intra-annual variability of these outbreaks. In the sensitivity analysis we discuss how the mortality rates change if we consider annual mean rather than median $\mathrm{DU}_{2.5}$ concentrations. Model evaluation based on in situ and remote sensing observations indicates that the simulations reproduce the atmospheric distribution of dust in time and space. The seasonal distribution of aerosol optical depth is well represented by the model, and the model results largely agree with observed $\mathrm{PM}_{2.5}$ and desert dust concentrations and deposition (Pozzer et al., 2012a, b; de Meij et al., 2012; Astitha et al., 2012).

We used population statistics for the year 2005, on a country level from the United Nations Department of Economic and Social Affairs (UNDES 2011) database and gridded global population numbers from the Columbia University Center for International Earth Science Information Network (CIESIN) database with a resolution of $2.5 \times 2.5$ arc minutes (ca. $0.04^{\circ} \times 0.04^{\circ}$; CIESIN, 2005). We used the global population of $30 \mathrm{yr}$ and older for the population variable (Pop) in the health impact function to be consistent with the ACS CPS-II cohort epidemiological research. The global population of $30 \mathrm{yr}$ and older was computed by applying the fraction of people of age $\geq 30$ in each country, to the appropriate grid cells of CIESIN data to obtain the total and gridded target populations.

We also estimate the YLL of the defined populations ( $30 \mathrm{yr}$ and older) by applying the calculated premature mortality caused by dust pollution to the following function:

$\Delta \mathrm{YLL}=\Delta \operatorname{Mort}\left(\mathrm{YLL}_{0} / y_{0}\right)$

where $\triangle$ YLL is the YLL due to premature mortality caused by airborne desert dust $\mathrm{DU}_{2.5}, \mathrm{YLL}_{0}$ is the baseline YLL and $y_{0}$ is the baseline mortality rate. Baseline YLL refer to years of life lost from cardiopulmonary diseases and lung cancer. Again, the link with lung cancer is considered to be more speculative. Data were obtained from the WHO Health Statistics and Health Information System for the year 2004 with $3 \%$ discounting and age weights, where younger ages are given a higher weight than the later years in an individual's life (WHO, 2008).

We carried out a statistical uncertainty analysis assuming random errors by propagating the quantified errors of all terms in Eq. (1), estimated from the $95 \%$ confidence intervals (CI95) reported in the ACS studies. A detailed analysis of our uncertainty methodology is presented in Lelieveld et al. (2013).

The used health impact function and RRs are based on the most comprehensive epidemiological cohort studies available, and are widely acknowledged as being the most representative (for a discussion we refer to Lelieveld et al., 2013). In the next section, we present the calculated global dust $\mathrm{DU}_{2.5}$ concentrations, the premature (excess) mortality due to dust and the associated YLL. The calculations have been performed at the resolution of the most detailed data set (i.e., $0.04^{\circ}$ of the population data) and then aggregated to higher levels up to those of countries.

\section{Results}

The global median modeled dust $\mathrm{DU}_{2.5}$ concentrations $\left(\mu \mathrm{g} \mathrm{m}^{-3}\right)$ for 2005 are presented in Fig. 1. To calculate the premature mortality due to long-term exposure to desert dust we applied a "clean air" global background dust concentration threshold of $7.5 \mathrm{\mu g} \mathrm{m}^{-3}$, below which we assume that dust does not have negative effects on human health. Model calculated regional distributions and budgets of aerosol pollution are discussed in Pozzer et al. (2012b). The regions most strongly affected by mineral dust particles are North Africa, the Middle East, South and East Asia.

Applying the health impact function (Eq. 1) for the population of $30 \mathrm{yr}$ in age and older to our model output suggests a significant contribution of desert dust to premature human mortality. We estimate that the exposure of the global population ( $\geq 30 \mathrm{yr}$ ) to ambient $\mathrm{DU}_{2.5}$ levels in the year 2005 caused about 402000 premature deaths by cardiopulmonary disease, CPD (i.e., an annual mortality of 137 per million capita). The countries with the highest premature mortality in 2005, caused by CPD, are Egypt with about 70000 , Pakistan with about 52000 , and Nigeria with 41000 . Other countries with high mortality due to dust are China, Sudan, India, Iraq, Saudi Arabia, Iran, and Niger with several thousand 
Table 1. Top twenty countries with the highest annual dust $\left(\mathrm{DU}_{2.5}\right)$ induced cardiopulmonary and lung cancer mortality for the population $\geq 30$ years old in 2005 .

\begin{tabular}{|c|c|c|c|c|c|c|c|c|}
\hline \multicolumn{9}{|c|}{ DUST $\left(\mathrm{DU}_{2.5}\right)$} \\
\hline & \multicolumn{4}{|c|}{ Cardiopulmonary mortality } & \multicolumn{4}{|c|}{ Lung cancer } \\
\hline & \multicolumn{2}{|c|}{ Total (thousands) } & \multicolumn{2}{|l|}{$\%$ per capita } & \multicolumn{2}{|l|}{ Total (thousands) } & \multicolumn{2}{|l|}{$\%$ per capita } \\
\hline 1 & Egypt & 70 & Mauritania & 0.46 & China & 2.5 & Turkmenistan & 0.013 \\
\hline 2 & Pakistan & 52 & Niger & 0.46 & Pakistan & 1.3 & Iraq & 0.007 \\
\hline 3 & Nigeria & 41 & Iraq & 0.29 & Egypt & 0.8 & Mauritania & 0.006 \\
\hline 4 & China & 32 & Egypt & 0.26 & Sudan & 0.6 & Niger & 0.006 \\
\hline 5 & Sudan & 25 & Mali & 0.25 & Iraq & 0.5 & Sudan & 0.006 \\
\hline 6 & India & 23 & Chad & 0.24 & Nigeria & 0.5 & Saudi Arabia & 0.005 \\
\hline 7 & Iraq & 22 & Sudan & 0.23 & India & 0.5 & Kuwait & 0.004 \\
\hline 8 & Saudi Arabia & 19 & Senegal & 0.21 & Saudi Arabia & 0.4 & United Arab Emirates & 0.004 \\
\hline 9 & Iran & 19 & Saudi Arabia & 0.21 & Iran & 0.4 & Palestinian Territory & 0.004 \\
\hline 10 & Niger & 16 & Turkmenistan & 0.20 & Turkmenistan & 0.3 & Mali & 0.003 \\
\hline 11 & Algeria & 11 & Kuwait & 0.18 & Niger & 0.2 & Bahrain & 0.003 \\
\hline 12 & Mali & 8 & United Arab Emirates & 0.17 & Algeria & 0.1 & Chad & 0.003 \\
\hline 13 & Chad & 6 & Gambia & 0.16 & Morocco & 0.1 & Libyan Arab Jamahiriya & 0.003 \\
\hline 14 & Senegal & 6 & Burkina Faso & 0.13 & Mali & 0.1 & Qatar & 0.003 \\
\hline 15 & Morocco & 5 & Libyan Arab Jamahiriya & 0.13 & Syrian Arab Republic & 0.1 & Egypt & 0.003 \\
\hline 16 & Burkina Faso & 4 & Bahrain & 0.13 & Yemen & 0.1 & Senegal & 0.003 \\
\hline 17 & Syrian Arab Republic & 4 & Qatar & 0.13 & Afghanistan & 0.1 & Pakistan & 0.003 \\
\hline 18 & Mauritania & 4 & Guinea-Bissau & 0.12 & Chad & 0.1 & Israel & 0.002 \\
\hline 19 & Turkmenistan & 4 & Nigeria & 0.11 & Kazakhstan & 0.1 & Gambia & 0.002 \\
\hline 20 & Yemen & 4 & Pakistan & 0.10 & Senegal & 0.1 & Mongolia & 0.002 \\
\hline
\end{tabular}

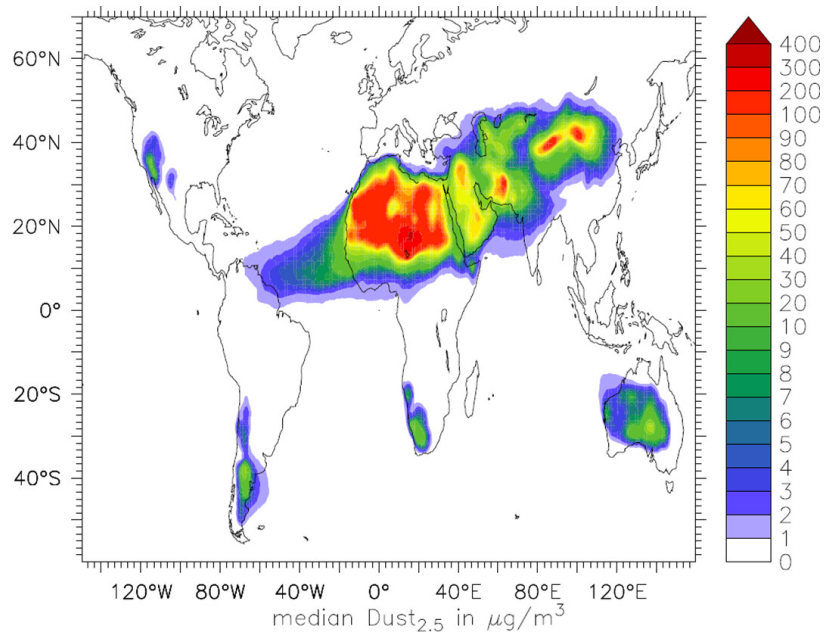

Fig. 1. Model calculated median dust concentrations $\left(\mathrm{DU}_{2.5}\right.$ in $\mu \mathrm{g} \mathrm{m}^{-3}$ ) in 2005 .

premature deaths. Unsurprisingly, these countries are located in the "dust belt", an area of strong desert dust sources that extends from the west coast of North Africa, through the Middle East, South and central Asia to eastern China. When premature mortality is normalized to the number of individuals the country ranking changes significantly, with Mauritania, Niger and Iraq being the top three countries with highest per capita excess mortality, followed by Egypt, Mali, Chad, Sudan, Senegal, Saudi Arabia, and Turkmenistan (Table 1).
Egypt, Pakistan and Nigeria, which are the top three countries in absolute numbers, are the 4th, 20th, and 19th, respectively, in the per capita ranking. This is related to the much higher population densities of the latter three countries compared to Mauritania, Niger and Iraq. An estimated global total of about 3.47 million YLL is caused by dust induced CPD.

Dust has a smaller impact through lung cancer mortality compared to CPD. We estimate globally about 9800 deaths in 2005 ( 3 deaths per million capita per year). The countries with highest premature mortality caused by dust-induced lung cancer are China with about 2500 deaths, Pakistan with about 1300, Egypt with about 800, and Sudan, Iraq, Nigeria, India, Saudi Arabia, Iran and Turkmenistan with several hundred deaths per year. The ranking of countries with the highest per capita mortality differs from the absolute ranking, with Turkmenistan, Iraq and Mauritania being the top three (Table 1). Similar to the CPD mortality rankings this difference is related to the smaller population densities in the latter countries. Globally, dust particles are estimated to cause about 96000 YLL due to lung cancer. Also unsurprisingly, almost all lung cancer mortality is found to occur in the dust belt. We emphasize that these numbers are particularly uncertain as it is not known if dust has the same impact on lung cancer mortality as ambient $\mathrm{PM}_{2.5}$. However, in countries with large urban and industrial centers (like China, Egypt, Pakistan, Iran), where both dust and anthropogenic pollution concentrations are high, and can rapidly mix, it is likely that the toxicity of dust does not deviate from other 


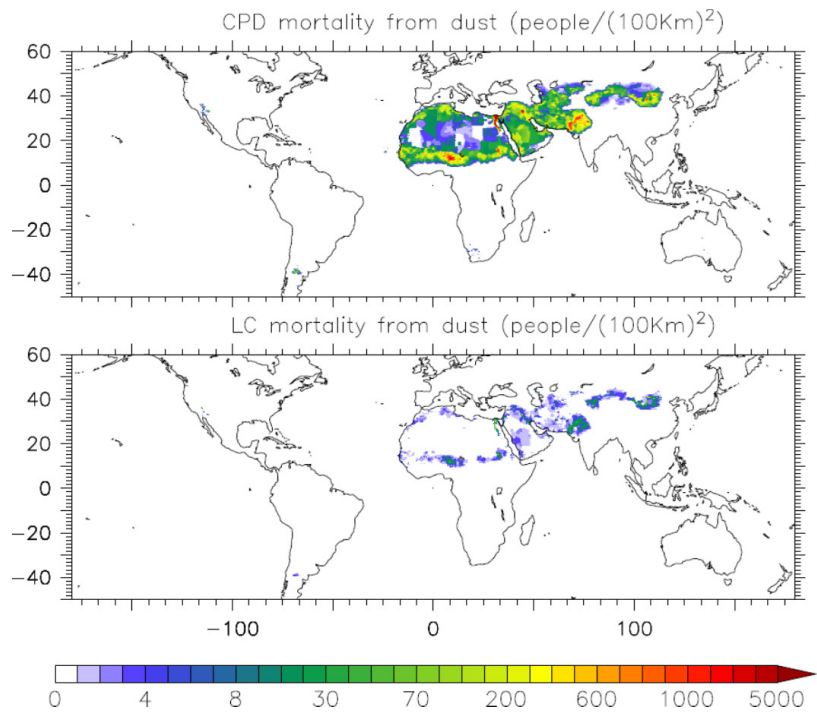

Fig. 2. Global premature mortality by cardiopulmonary disease (top) and lung cancer (bottom) (in individuals per $100 \times 100 \mathrm{~km}^{2}$ ) due to dust $\left(\mathrm{DU}_{2.5}\right.$ ) for the population $\geq 30 \mathrm{yr}$ in 2005 .

particulate constituents, and may act in the lungs similarly to other $\mathrm{PM}_{2.5}$ compounds.

The quantified errors of all terms in Eq. (1), estimated from the $95 \%$ confidence intervals (CI95) reported in the ACS studies, shows that the global mortality estimates are quite robust with an uncertainty up to about $\pm 5 \%$ for annual global dust induced mortality. At the country level the uncertainties are much higher (exceeding $\pm 100 \%$ ) for some countries in North Africa and Middle East. Here we only address statistical uncertainty. Non-representativeness of the applied concentration response factors outside the USA, the properties and toxicity of the different $\mathrm{PM}_{2.5}$ components and the shape of CRF add to the uncertainty. We discuss these issues in Sects. 4 and 5.

The global premature mortality by cardiopulmonary disease and lung cancer due to the long-term exposure to desert dust with an aerodynamic diameter $\leq 2.5 \mu \mathrm{m}$ is shown in Fig. 2. Table 1 shows the top 20 countries with the highest CPD and lung cancer mortality, and the top 20 countries with the highest per capita mortality caused by $\mathrm{DU}_{2.5}$. In Table 2 we present the percentage ratio of the country mortality due to CPD diseases and lung cancer caused by inhaling dust particles relative to the total (from all causes) CPD, and lung cancer mortality. We estimate that about $53 \%$ of the total CPD mortality in Mauritania and Niger is related to airborne desert dust. Iraq and Saudi Arabia are the third and the fourth in this ranking with about $35 \%$ and $34 \%$, respectively; Egypt follows with about $32 \%$ and Mali with $30 \%$. In total 15 countries in and around the dust belt zone have a fraction of $20 \%$ and higher, while about $1.8 \%$ of the total global CPD mortality is caused by the long-term exposure to desert dust $\mathrm{DU}_{2.5}$. The fractions and ranking of the countries
Table 2. Top twenty countries with the highest percentage of dust $\left(\mathrm{DU}_{2.5}\right)$ induced cardiopulmonary and lung cancer mortality relative to total CPD and LC mortality (for the population $\geq 30 \mathrm{yr}$ old in 2005).

\begin{tabular}{lllll}
\hline \multicolumn{4}{c}{ Percent dust induced mortality relative to all causes } \\
\hline \multicolumn{4}{c}{ Cardiopulmonary } & \multicolumn{2}{c}{ Lung cancer } \\
\hline 1 & Mauritania & 53 & Mauritania & 55 \\
2 & Niger & 53 & Niger & 55 \\
3 & Iraq & 35 & Iraq & 36 \\
4 & Saudi Arabia & 34 & Saudi Arabia & 35 \\
5 & Egypt & 32 & Egypt & 34 \\
6 & Mali & 30 & Mali & 31 \\
7 & Kuwait & 29 & Kuwait & 30 \\
8 & United Arab Emirates & 28 & United Arab Emirates & 29 \\
9 & Chad & 28 & Sudan & 29 \\
10 & Sudan & 28 & Chad & 28 \\
11 & Senegal & 24 & Senegal & 26 \\
12 & Libyan Arab Jamahiriya & 21 & Libyan Arab Jamahiriya & 22 \\
13 & Bahrain & 21 & Bahrain & 22 \\
14 & Qatar & 21 & Qatar & 22 \\
15 & Turkmenistan & 20 & Turkmenistan & 21 \\
16 & Gambia & 19 & Gambia & 20 \\
17 & Burkina Faso & 15 & Burkina Faso & 16 \\
18 & Oman & 15 & Oman & 16 \\
19 & Guinea-Bissau & 14 & Guinea-Bissau & 15 \\
20 & Syrian Arab Republic & 13 & Syrian Arab Republic & 14 \\
& & & &
\end{tabular}

are similar for lung cancer (Table 2). Mauritania and Niger are the top two in the ranking with about $55 \%$ of the total lung cancer mortalities attributed to airborne desert dust, and Iraq follows with about $36 \%$. In total 16 countries have a fraction of $20 \%$ and higher, while $0.7 \%$ of the total global lung cancer mortality is related to the long-term exposure to desert dust. Mauritania, Niger and some other countries in the dust belt are very close to the main Saharan dust sources, and the populations are exposed to high concentrations of $\mathrm{DU}_{2.5}$ throughout the year (median concentrations in inhabited areas from 20 to $150 \mu \mathrm{g} \mathrm{m}^{-3}$ or more, and much higher annual mean concentrations). The fraction of the population $\geq 30 \mathrm{yr}$ in some of these countries is relatively small (e.g., $30 \%$ and $27 \%$ for Mauritania and Niger, respectively) and the baseline mortality rates high (WHO, 2003).

\section{Sensitivity calculations}

For our central calculations we used a threshold dust concentration of $7.5 \mu \mathrm{g} \mathrm{m}^{-3}$, assuming that below this level the long-term exposure to $\mathrm{DU}_{2.5}$ does not contribute to mortality. Similar thresholds for $\mathrm{PM}_{2.5}$ were also applied in several previous studies (Ezzati et al., 2002; Ostro, 2004; Cohen et al., 2005). In contrast, some studies assume that $\mathrm{PM}_{2.5}$ can be harmful for human health even at lower concentrations (WHO, 2004, 2005). Since the use of such thresholds is not unambiguous, we performed a sensitivity analysis assuming different threshold concentrations (i.e., 0 , 5, and $10 \mu \mathrm{g} \mathrm{m}^{-3}$ ) 


\section{CPD mortality 2005}

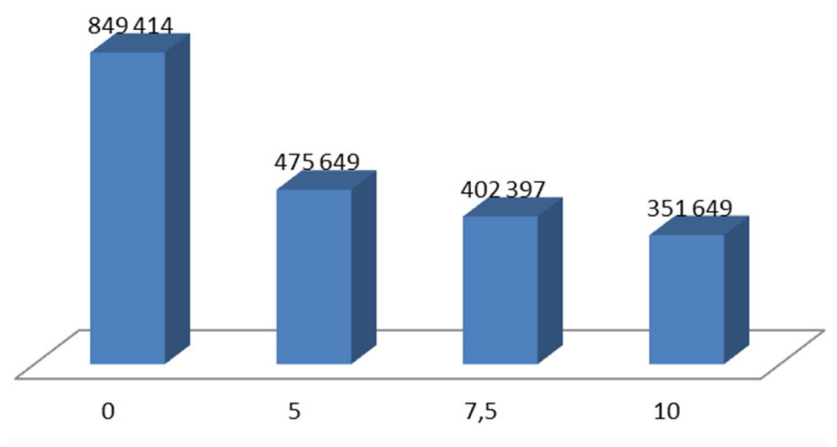

LC mortality 2005

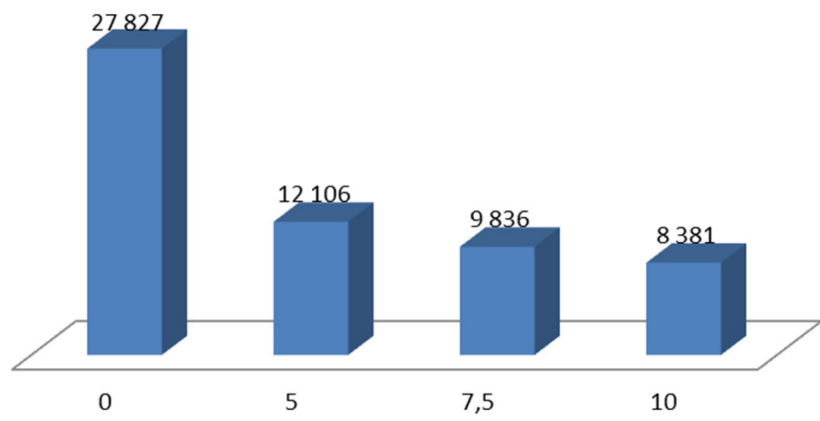

Fig. 3. Total premature mortality by cardiopulmonary disease (top) and lung cancer (bottom) due to dust $\left(\mathrm{DU}_{2.5}\right)$ for the population $\geq 30$ years in 2005 . Mortality calculations are based on four different background dust concentrations $\left(0,5,7.5\right.$ and $\left.10 \mu \mathrm{g} \mathrm{m}^{-3}\right)$.

and apply the same methodology to compare to our central results (with $7.5 \mu \mathrm{g} \mathrm{m}^{-3}$ ).

When we do not assume a threshold concentration, we estimate that the exposure of the global population of age $30 \mathrm{yr}$ and older to ambient $\mathrm{DU}_{2.5}$ levels in the year 2005 caused about 849000 deaths by CPD (290 deaths per million capita) and about 27800 by lung cancer ( 9 deaths per million capita). When we assume a threshold of $5 \mu \mathrm{g} \mathrm{m}^{-3}$, we estimate an excess mortality of about 476000 deaths by CPD (162 deaths per million capita) and 12100 by lung cancer (4 deaths per million capita). For the case of the highest threshold of $10 \mu \mathrm{g} \mathrm{m}^{-3}$, we estimate 352000 deaths by CPD (120 deaths per million capita) and 8400 by lung cancer ( 3 deaths per million capita). The associated total (from both CPD and lung cancer) YLL are about 7.2, 4.2 and 3.1 million years (for $0,5,10 \mu \mathrm{g} \mathrm{m}^{-3}$ ). Figure 3 shows the calculated global annual mortality due to $\mathrm{DU}_{2.5}$ for 2005 for the 4 cases. The comparison of the theoretical case of nondust (zero background concentration) in the atmosphere to our central results $\left(7.5 \mu \mathrm{g} \mathrm{m}^{-3}\right)$ yields about 2.1 times higher CPD mortality and 2.8 times higher lung cancer mortality. The use of $5 \mu \mathrm{g} \mathrm{m}^{-3}$ as the global background dust concen- tration increases CPD and lung cancer mortality due to $\mathrm{DU}_{2.5}$ by about 1.2 times compare to the $7.5 \mu \mathrm{g} \mathrm{m}^{-3}$ threshold, while the use of $10 \mu \mathrm{g} \mathrm{m}^{-3}$ somewhat decreases the annual mortality (about 0.9 times relative to the $7.5 \mu \mathrm{g} \mathrm{m}^{-3}$ for both $\mathrm{CPD}$ and lung cancer). The number of countries with significant numbers of deaths expands by reducing the background from $7.5 \mu \mathrm{g} \mathrm{m}^{-3}$ to 0 dust concentrations, including countries from other regions like Turkey, USA, Russia, Ukraine, Japan, Mexico, Italy, Greece, Brazil, Spain and others. Therefore, by applying $7.5 \mu \mathrm{g} \mathrm{m}^{-3}$ our results may be considered conservative.

In a second sensitivity case, we used the mean instead of the 2005 median dust $\left(\mathrm{DU}_{2.5}\right)$ concentrations. In the longterm health impact studies and reports as well as in the European and United States Clean Air Directives, annual mean concentrations are used for the particulate matter pollution. As mentioned earlier, in this study we used median concentrations for our main analysis to limit the effect of severe episodic dust outbreaks, which would drive annual mean concentrations towards much higher levels. The justification for using the median is that during severe dust events people might limit exposure by avoiding outdoor activity. It is however interesting to examine how the excess mortality would change if we use annual mean concentrations for our calculations. For this case study, we use the $7.5 \mu \mathrm{g} \mathrm{m}^{-3}$ threshold dust concentration.

Following the same methodology, we calculate about 622000 premature deaths from CPD (212 per million capita), and 16300 from lung cancer (6 per million capita) globally. Hence the use of annual mean $\mathrm{DU}_{2.5}$ concentrations in the health impact function (Eq. 1) increases the excess mortality by more than half to 220000 individuals by CPD and 6500 by lung cancer compared to the central study with median dust concentrations. The associated YLL are 5.3 million and 156000 years for CPD and lung cancer, respectively. The ranking of the countries with relatively high premature mortality is not significantly influenced by this assumption. Also because of this choice of using medians rather than means, our central results should be considered conservative.

In a last sensitivity case we discuss the shape of the CRF. The use of a log-linear exposure function has been recommended such that its slope would flatten at higher $\mathrm{PM}_{2.5}$ concentrations when estimating health risk beyond the highest air pollution levels observed in epidemiological studies (e.g., $30 \mu \mathrm{g} \mathrm{m}^{-3} \mathrm{PM}_{2.5}$ ) (Cohen et al., 2004; Ostro 2004; Krewski et al., 2009). In the dust belt, $\mathrm{DU}_{2.5}$ median and mean concentrations can exceed this threshold. We use the following relative risk function to estimate the log-linear exposure mortality from CPD and lung cancer:

$R R=[(X+1) /(X o+1)]^{\beta}$.

The log-linear risk coefficients are based on Krewski et al (2009) (CPD: $\beta=0.18878$ (95\% CI: 0.12343-0.25385); LC: $\beta=0.21136$ (95\% CI: $0.10807-0.31562)$ ). $X$ refers to the 
Table 3. Total number of global cardiopulmonary and lung cancer deaths for the population $\geq 30 \mathrm{yr}$ old in 2005 (in thousands), due to dust $\left(\mathrm{DU}_{2.5}\right.$ ), under the central assessment (in bold) and the five sensitivity cases.

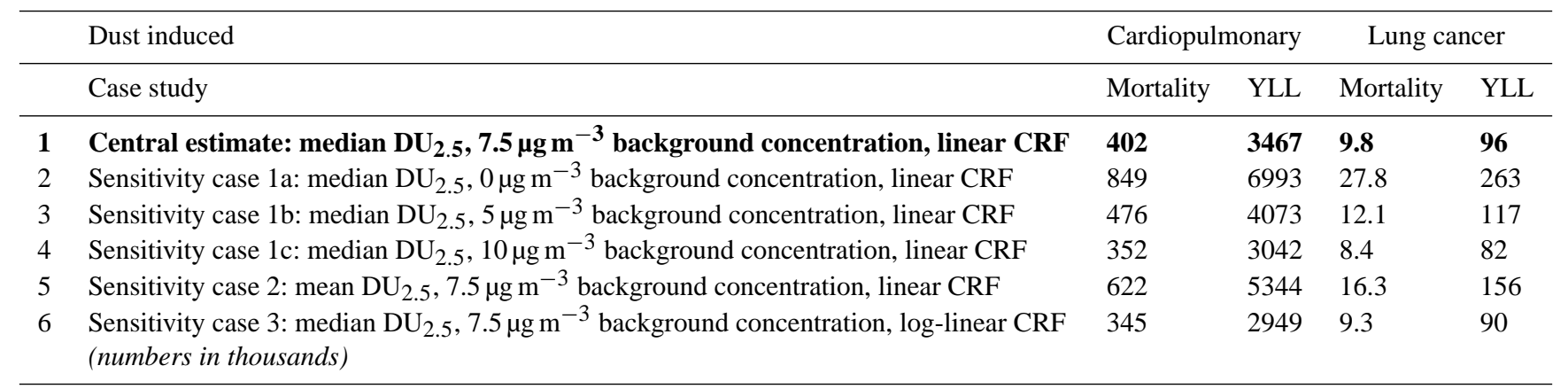

median $\mathrm{DU}_{2.5}$ concentrations in 2005 and $X o$ is the background concentration $\left(X o=7.5 \mu \mathrm{g} \mathrm{m}^{-3}\right.$ as in the central calculations). We use the following general health impact function to estimate the excess in mortality:

$\Delta$ Mort $=y_{0} \cdot A F \cdot$ Pop

where $A F$ is the fraction of the disease burden attributable to the risk factor (here $\mathrm{DU}_{2.5}$ ), based in this sensitivity case on the log-linear exposure function and defined as

$A F=(R R-1) / R R$.

We estimate about 345000 deaths from CPD (118 deaths per million capita) and about 9300 deaths from lung cancer (3 deaths per million capita) for the global population ( $\geq 30 \mathrm{yr}$ ) in 2005. The associated YLL are about 2.95 million and 90000 years for CPD and lung cancer, respectively. The ranking of the countries with relatively high premature mortality is not significantly changed.

The comparison of the above estimates to our base case estimates shows that when we assume a log-linear CRF the excess in mortality is about $14 \%$ lower for CPD and about $6 \%$ lower for lung cancer. The shape of the CRF does not strongly affect our estimates, especially for the case of lung cancer. Our outcome agrees with other studies (Roman et al., 2008; Pope et al., 2011; Evans et al., 2012), indicating that the exposure function is more critical in regions with relatively low $\mathrm{PM}_{2.5}$ concentrations. We will further discuss this sensitivity case in the next section. Table 3 summarizes the total global estimated numbers of deaths from dust induced CPD and lung cancer mortality, and the associated YLL for the central assessment and the five sensitivity cases.

\section{Discussion}

As indicated earlier there is a lack of epidemiological cohort studies in regions that are strongly affected by airborne desert dust, notably in the dust belt. The concentration-response functions applied here have been based on epidemiological cohort studies by the American Cancer Society (ACS), which may not be representative for countries in which $\mathrm{DU}_{2.5}$ dominates $\mathrm{PM}_{2.5}$. The toxicity of chemical components of $\mathrm{PM}_{2.5}$ in different parts of the world, the way each compound acts onto the cardiovascular and respiratory systems and the exposure conditions are not necessarily the same. In the countries in and around the dust belt, where exposure conditions may be different from the USA and where high baseline mortality rates prevail, region specific epidemiological cohort studies are needed (Cohen et al., 2005; De Longueville et al., 2013). A critical assumption in this work is, therefore, that desert dust $\mathrm{DU}_{2.5}$ has the same health impact as $\mathrm{PM}_{2.5}$ in the ACS epidemiological study. Despite this limitation, our estimates are based on this study because it is the most comprehensive one, and is considered as one of the best available sources of data on the risk of mortality associated with long-term exposure to $\mathrm{PM}_{2.5}$ and is also considered representative for other regions (Cohen et al., 2004; COMEAP, 2009; Krewski et al., 2009; Evans et al., 2012). The proportion of dust in this study, from which epidemiologic CRFs were derived, is not known so these response functions likely incorporate some impact of dust exposure. It should be emphasized that although some experts classify all $\mathrm{PM}_{2.5}$ components as equally toxic, others consider $\mathrm{DU}_{2.5}$ the least toxic aerosol constituent (Cooke et al., 2007). For that reason the premature mortality estimates presented here are chosen to be relatively conservative (i.e., using the median and $7.5 \mu \mathrm{g} \mathrm{m}^{-3}$ threshold concentrations).

The assumption about the relationship between mortality and the exposure to $\mathrm{PM}_{2.5}$ contributes to the uncertainties. Several studies use both linear and log-linear functions for the shape of the CRF (Pope et al., 2002; Cohen et al., 2004; Ostro et al., 2004; Krewski et al., 2009; Pope et al., 2009, 2011). For higher $\mathrm{PM}_{2.5}$ concentrations than $30 \mu \mathrm{g} \mathrm{m}^{-3}$ there is no clear evidence which is the optimum shape of CRF for $\mathrm{CPD}$ and lung cancer mortality attributable to $\mathrm{PM}_{2.5}$. Pope et al. (2011) conclude in their discussion that for cardiovascular mortality the exposure response function is non-linear with a steep increase in risk at low exposures and flattening out at higher exposures. For lung cancer they found that a 
nearly linear response function can be appropriate. Cohen et al. (2004) presented sensitivity analyses to compare to their base-case estimates, in which the burden of disease was estimated by applying the ACS CRF over the range of 7.5$50 \mu \mathrm{g} \mathrm{m}^{-3}$. In the sensitivity analysis they considered three alternatives: (case 1) no increase in excess mortality above $30 \mu \mathrm{g} \mathrm{m}^{-3} \mathrm{PM}_{2.5}$, (case 2) excess mortality increases linearly above $30 \mu \mathrm{g} \mathrm{m}^{-3} \mathrm{PM}_{2.5}$, and (case 3) excess mortality increases with the $\log$ of concentration of $\mathrm{PM}_{2.5}$ across the entire range. They found that in case 1 , excess mortality estimates decrease by $27-29 \%$, worldwide. The extrapolation of the ACS coefficients to the higher $\mathrm{PM}_{2.5}$ concentrations on the linear and logarithmic scales (cases 3 and 4 respectively), results in increases of $10 \%$ and $12 \%$ in the estimated CPD mortality, and $8 \%$ and $24 \%$ in the estimated lung cancer mortality, relative to the base-case estimates. In case 2, mortality increases in eastern and South/southeastern Asia and in regions in North Africa and Middle East. In case 3, mean excess mortality is calculated to be about $63 \%$ higher in regions with relatively low $\mathrm{PM}_{2.5}$ concentrations (e.g., USA, Europe), while the mortality in regions with high concentrations remained unchanged or slightly reduced (Cohen et al., 2004). Evans et al (2012) obtained similar results. In their study mortality was substantially greater under the log-linear versus the linear case for regions with relatively low concentrations of $\mathrm{PM}_{2.5}$. However, global mortality estimates were only slightly higher with the log-linear compared to linear case, since the regions with large populations and high pollution levels, which contribute most to the global mortality, had lower mortality estimates under the log-linear case (Evans et al., 2012). Our analysis shows that in regions with high $\mathrm{PM}_{2.5}$ exposure like the dust belt (where dust dominates total particulate pollution) the excess mortality due to $\mathrm{DU}_{2.5}$ is slightly lower (about $14 \%$ and $6 \%$ for CPD and LC respectively) with the log-linear exposure function compared to the linear CRFs. As indicated in previous studies, the shape of the CRF is more critical at lower $\mathrm{PM}_{2.5}$ concentrations, where the largest uncertainty in estimated effects on mortality is expected (Cohen et al., 2004; Roman et al., 2008; Evans et al., 2012).

Many epidemiological studies have demonstrated that atmospheric $\mathrm{PM}_{2.5}$ causes mortality and hospital admissions as a result of CPD and lung cancer. However, only a small number of studies examine the health responses due to Saharan and other dust sources (De Longueville et al., 2010, 2013; Karanasiou et al., 2012). These studies that address health effects of desert dust particles are based on time-series analyses in specific regions (e.g., Mediterranean cities). Timeseries studies mainly assess the short-term effects of particulate matter pollution on health, by relating day-to-day variations in air pollution to mortality and morbidity counts within the same geographical area. The main metric they use is the dust particle mass and not chemical constituents. A systematic review by De Longuivelle et al. (2013) of the available literature on the relationship between desert dust, air qual- ity and human health has highlighted notable gaps. Their survey emphasizes clear impacts of dust on human health and mortality in many parts of the world (e.g., Bell et al., 2008; Mallone et al., 2011; Nastos et al., 2011; Neophytou et al., 2013; Perez et al., 2008; Sajani et al., 2011, and others). Further, studies reported that in Korea, dust events are associated with increased daily mortality (Lee et al., 2007). Saharan dust outbreaks have been associated with an increased daily mortality of $8.4 \%$ per $10 \mu \mathrm{g} \mathrm{m}^{-3}$ in $\mathrm{PM}_{10-2.5}$ in Barcelona, Spain (Perez et al., 2008). Mallone et al. (2011) found evidence of effects of $\mathrm{PM}_{2.5-10}$ and $\mathrm{PM}_{10}$ on natural and cause-specific mortality in Rome, Italy, with stronger estimated effects on cardiac mortality during Saharan dust outbreaks. They estimated the respiratory mortality due to increases in $\mathrm{PM}_{2.5-10}\left(10.8 \mu \mathrm{g} \mathrm{m}^{-3}\right)$ to range from $2.64 \%$ to $12.65 \%$ (with a $95 \%$ CI of $1.18-25.42 \%$ ). Associations of $\mathrm{PM}_{2.5-10}$ with cardiac induced mortality were stronger on Saharan dust days $(9.73 \%$; $95 \%$ CI, $4.25-15.49 \%)$ than on dust-free days $(0.86 \%$; $95 \% \mathrm{CI},-2.47 \%$ to $4.31 \%)$. Neophytou et al. (2013) found a $2.43 \%$ (95\% CI: 0.53 , 4.37) increase in daily cardiovascular mortality associated with each $10 \mu \mathrm{g} \mathrm{m}^{-3}$ increase in $\mathrm{PM}_{10}$ concentrations on dusty days. De Longuivelle et al. (2013) pointed to the imbalance between the areas most exposed to dust and the areas most studied in terms of health effects. For example, health effects of dust in eastern Asian countries appear to be relatively frequently studied, as well as health effects due to Saharan and other desert dust sources in Europe and America. However, no study about the dust impact on health in West Africa has been published thus far, despite the proximity of the Sahara where dust events are more frequent and intense than anywhere else in the world. Our results on the global premature mortality rates caused by mineral dust cannot be directly compared to the above short-term effect studies, because our methodology is based on long-term epidemiological cohort studies. Short-term mortality impacts represent a very small percentage of the total mortality impact (Roman et al., 2008). Our results nevertheless reinforce many of the previous findings, showing a substantial increase of mortality and morbidity in relation to dust events, which will hopefully help motivate continued epidemiological investigations, including cohort studies.

In a recent study, Evans et al. (2012) estimated the expected number of deaths from all causes, cardiopulmonary diseases, lung cancer and ischemic heart disease, due to chronic $\mathrm{PM}_{2.5}$ exposure. They used risk coefficients based on the ACS cohort study and $\mathrm{PM}_{2.5}$ concentrations from satellite retrievals. In their assessment they accounted for $\mathrm{PM}_{2.5}$ _total and $\mathrm{PM}_{2.5}$ no dust. They found that the $\mathrm{PM}_{2.5}$ mortality in the Mediterranean region (several countries in North Africa and Middle East) was mainly related to the non-anthropogenic component of total $\mathrm{PM}_{2.5}$. In their base case scenario (linear CRF, reference exposure $5.8 \mu \mathrm{g} \mathrm{m}^{-3}$ ), they estimated about 2.48 million deaths for CPD and 222000 for lung cancer attributed to total $\mathrm{PM}_{2.5}$, and about 1.65 million and 170000 
CPD and lung cancer deaths, respectively, after the removal of the natural dust component in 2004. The difference of about 830000 for CPD and 52000 for lung cancer in mortality indicates the impact of natural dust. These estimates show significantly higher dust-induced global mortality compared to our central assessment, and compared to the sensitivity case where we used annual mean dust concentrations. The use of $5.8 \mu \mathrm{g} \mathrm{m}^{-3}$ as background $\mathrm{PM}_{2.5}$ concentration (we used $7.5 \mu \mathrm{g} \mathrm{m}^{-3}$ ), and annual mean $\mathrm{PM}_{2.5 \text { _total }}$ and $\mathrm{PM}_{2.5}$ no dust satellite concentrations (we used modeled median or mean $\mathrm{DU}_{2.5}$ concentrations) may explain to some extent the discrepancies.

In this analysis we focus on the enhanced mortality due to mineral desert dust. Other sources like road dust, dust from industrial activities, agricultural and other human activities are not included as they are not represented in our emission database. Further, our model does not account for re-suspension of dust after its deposition, which may be especially important in the urban environment. The impact of anthropogenic $\mathrm{PM}_{2.5}$ on the dust properties is also not examined. Dust outbreaks may also cause health impacts due to the simultaneous atmospheric transport of anthropogenic pollution (Erel et al., 2007; Kallos et al., 2007) and of harmful micro-organisms (Polymenakou et al., 2008). It has been observed that dust particles rapidly mix with acids and organic components (Ma et al., 2010), which can be relevant for large urban and industrial centers (e.g., Cairo, Beijing, Tehran etc.) where both dust and anthropogenic pollution concentrations are high. In these areas it is likely that the toxicity of dust does not deviate from other particulate constituents of the same size category. Altogether, using the median rather than the mean, applying a threshold background level of $7.5 \mu \mathrm{g} \mathrm{m}^{-3}$, not accounting for $\mathrm{DU}_{2.5}$ sources other than desert dust, neglecting particle re-suspension and only accounting for the age category of $\geq 30 \mathrm{yr}$ likely cause our estimates to represent a lower limit, in spite of $\mathrm{DU}_{2.5}$ being perhaps less toxic than $\mathrm{PM}_{2.5}$.

\section{Conclusions}

We applied a human health impact function to modeled global fine particulate matter concentrations to estimate the premature mortality caused by the long-term exposure to airborne desert dust with an aerodynamic diameter $\leq 2.5 \mu \mathrm{m}$ in the year 2005. Our model results indicate a large number of premature deaths by cardiopulmonary disease and a significant number of deaths by lung cancer, mostly in the dust belt region between North Africa and eastern China. We estimate a total number of premature deaths of about 412000 from cardiopulmonary diseases and lung cancer, and 3.56 million YLL per year. The countries with the highest dust related mortality are Egypt, Pakistan, Nigeria, China, Sudan and other countries in and around the dust belt. If we consider the per capita mortality, the ranking changes, with Maurita- nia, Niger, Iraq, Egypt and Mali being the top five counties with the highest per capita mortality. We estimate the global per capita mortality caused by $\mathrm{DU}_{2.5}$ to be about $0.014 \%$ per year, while the global fraction of the total cardiopulmonary and lung cancer deaths caused by exposure to desert dust is about $1.7 \%$.

We performed a sensitivity analysis by applying different background levels below which no health effects are assumed. The threshold concentration appears to sensitively influence our results, indicating more than twice the number of premature deaths ( 877000 /year) when we assume that no threshold exists below which $\mathrm{DU}_{2.5}$ does not influence health compared to our central estimate (412 000/year for a $7.5 \mu \mathrm{g} \mathrm{m}^{-3}$ threshold concentration). If we use annual mean $\mathrm{DU}_{2.5}$ concentrations for 2005 rather than median concentrations, the global number of premature deaths increases to $638000 \mathrm{yr}^{-1}$ (> 1.5 times higher compared to our central estimate). The use of a log-linear exposure function slightly reduces the mortality estimates by about $14 \%$ for CPD and $6 \%$ for lung cancer.

We stress that our results refer to the effects of fine particulate desert dust $\left(\mathrm{DU}_{2.5}\right)$ on the population of $\geq 30 \mathrm{yr}$ based on the CRFs from the epidemiological study by Krewski et al. (2009) based on the ACS/CPS-II cohort, which can be expected to cause significant uncertainty in our calculations for regions and countries for which these data may not be representative (i.e., outside the USA and Europe). We nevertheless believe that our central estimates of premature mortality due to $\mathrm{DU}_{2.5}$ are likely to represent lower limits.

\section{Appendix A}

Table A1. Abbreviations and acronyms.

\begin{tabular}{|c|c|}
\hline ACS/CPS & $\begin{array}{l}\text { American Cancer Society/Cancer Preven- } \\
\text { tion Study }\end{array}$ \\
\hline BMR & Baseline mortality rate \\
\hline CI & Confidence interval \\
\hline CIESIN & $\begin{array}{l}\text { Columbia University Center for Interna- } \\
\text { tional Earth Science Information Network }\end{array}$ \\
\hline CRF & Concentration response function \\
\hline CPD & Cardiopulmonary disease \\
\hline $\mathrm{DU}_{2.5}$ & $\begin{array}{l}\text { Dust particles with an aerodynamic diam- } \\
\text { eter smaller than } 2.5 \mu \mathrm{m}\end{array}$ \\
\hline ECHAM & European Centre Model Hamburg \\
\hline EMAC & $\begin{array}{l}\text { ECHAM/MESSy Atmospheric Chemistry, } \\
\text { MESSy Modular Earth Submodel System }\end{array}$ \\
\hline GBD & Global burden of disease \\
\hline ICD-10 & $\begin{array}{l}\text { International Classification of Diseases - } \\
\text { 10th revision }\end{array}$ \\
\hline LC & Lung cancer \\
\hline $\mathrm{PM}_{2 .}$ & $\begin{array}{l}\text { Particulate Matter with an aerodynamic di- } \\
\text { ameter smaller than } 2.5 \mu \mathrm{m}\end{array}$ \\
\hline
\end{tabular}




\begin{tabular}{|c|c|}
\hline $\mathrm{PM}_{2.5-10}$ & $\begin{array}{l}\text { Particulate matter with an aerodynamic di- } \\
\text { ameter between } 2.5 \mu \mathrm{m} \text { and } 10 \mu \mathrm{m}\end{array}$ \\
\hline $\mathrm{PM}_{10}$ & $\begin{array}{l}\text { Particulate matter with an aerodynamic di- } \\
\text { ameter smaller than } 10 \mu \mathrm{m}\end{array}$ \\
\hline Pop & Total population with an age of $\geq 30 \mathrm{yr}$ \\
\hline RR & Relative risk \\
\hline UNDES & $\begin{array}{l}\text { United Nations Department of Economic } \\
\text { and Social Affairs }\end{array}$ \\
\hline UNPD & United Nations Population Division \\
\hline & World Health Organization \\
\hline YLL & Years of life lost \\
\hline
\end{tabular}

Acknowledgements. The research leading to these results has received funding from the European Research Council under the European Union's Seventh Framework Programme (FP7/20072013)/ERC grant agreement no. 226144 . We are grateful to John S. Evans and colleagues at the Cyprus International Institute for Environmental and Public Health for fruitful discussions.

Edited by: X. Querol

\section{References}

Akimoto H.: Global air quality and pollution, Science, 302, 17161719, 2003.

Anenberg, S. C., Horowitz, L. W., Tong, D. Q., and West, J. J.: An estimate of the global burden of anthropogenic ozone and fine particulate matter on premature human mortality using atmospheric modeling, Environ. Health Perspect., 118, 1189-1195, 2010.

Anenberg, S. C., West, J. J., Horowitz, L. W., and Tong, D. Q.: The global burden of air pollution on mortality, Environ. Health Perspect., 119, 158-159, 2011.

Astitha, M., Lelieveld, J., Abdel Kader, M., Pozzer, A., and de Meij, A.: Parameterization of dust emissions in the global atmospheric chemistry-climate model EMAC: impact of nudging and soil properties, Atmos. Chem. Phys., 12, 11057-11083, doi:10.5194/acp-12-11057-2012, 2012.

Brook, R. D., Rajagopalan, S., Pope III, C. A., Brook, J. R., Bhatnagar, A., Diez-Roux, A. V., Holguin., F., Hong, Y., Luepker., R. V., Mittleman, M.A., Peters, A., Siscovick, D., Smith Jr., S. C., Whitsel, L., and Kaufman, J. D.: Particulate matter air pollution and cardiovascular disease - An update to the scientific statement from the American Heart Association, J. Am. Heart Assoc., doi:10.1161/CIR.0b013e3181dbece1, 2010.

Brunekreef, B. and Holgate, S. T.: Air pollution and health, The Lancet, 360, 1233-1242, 2002.

Center for International Earth Science Information Network (CIESIN), Columbia University; United Nations Food and Agriculture Programme (FAO) and Centro Internacional de Agricultura Tropical (CIAT): Gridded Population of the World, Version 3 (GPWv3): Population Density Grid, Future Estimates. Palisades, NY: Socioeconomic Data and Applications Center (SEDAC), Columbia University, available at: http://sedac.ciesin.columbia. edu/gpw (last access: July 2012), 2005.

Cohen, A. J., Anderson, H. R., Ostro, B., Pandey, K. D., Krzyzanowski, M., K"unzli, N., Gutschmidt, K., Pope, A.,
Romieu, I., Samet, J. M., and Smith, K.: Urban air pollution, chapter in: Comparative quantification of health risks, Global and regional burden of disease attributable to selected major risk factors, Volume 2, World Health Organization, Geneva, 2004.

Cohen, A. J., Anderson, H. R., Ostra, B., Pandey, K. D., Krzyzanowski, M., Künzli, N., Gutschmidt, K., Pope, A., Romieu, I., Samet, J. M., and Smith, K.: The global burden of disease due to outdoor air pollution, J. Toxicol. Environ. Health, $68,1-7,2005$.

Committee on the Medical Effects of Air Pollutants (COMEAP): Long-Term Exposure to Air Pollution: Effect on Mortality, Health Protection Agency, UK, ISBN 978-0-85951-640-2, 2009.

Cooke, R. M., Wilson, A. M., Tuomisto, J. T., Morales, O., Tainio, M., and Evans, J. S.: A probabilistic characterization of the relationship between fine particulate matter and mortality: Elicitation of European Experts, Environ. Sci. Technol., 41, 6598-6605, 2007.

De Longueville, F., Hountondji, Y.-C., Henry, S., and Ozer, P.: What do we know about effects of desert dust on air quality and human health in West Africa compared to other regions?, Sci. Total Environ. 409, 1-8, 2010.

De Longueville, F., Ozer, P., Doumbia, S., and Henry, S.: Desert dust impacts on human health: an alarming worldwide reality and a need for studies in West Africa, Int. J. Biometeorol., 57, 1-19, 2013.

De Meij, A., Pozzer, A., Pringle, K. J., Tost, H., and Lelieveld, J.: EMAC model evaluation and analysis of atmospheric aerosol properties and distribution, Atmos. Res, 114-115, 38-69, 2012.

Dockery, D. W., Pope III, C. A., Xu, X., Spengler, J. D., Ware, J. H., Fay, M. E., Ferris, B. G., and Speizer, F. E.: An association between air pollution and mortality in six U.S. cities, N. Engl. J. Med., 329, 1753-1759, 1993.

Erel, Y., Kalderon-Asael, B., Dayan, U., and Sandler, A.: European atmospheric pollution imported by cooler air masses to the Eastern Mediterranean during the summer, Environ. Sci. Technol., 41, 5198-5203, 2007.

Evans, J., van Donkelaar, A., Martin, R. V., Burnett, R., Rainham, D., Birkett, N. J., and Krewski, D.: Estimates of global mortality attributable to particulate air pollution using satellite imagery, Environ. Res., doi:10.1016/j.envres.2012.08.005, 2012.

Ezzati, M., Lopez, A. D., Rodgers, A., Hoorn, S. V., Murray, C. J. L, the Comparative Risk Assessment Collaborating Group: Selected major risk factors and global and regional burden of disease, Lancet, 360, 1347-1360, 2002.

European Environment Agency Technical Report: Particulate matter from natural sources and related reporting under the EU Air Quality Directive in 2008 and 2009, no. 10, 2012.

Forster, P., Ramaswamy, V., Artaxo, P., Berntsen, T., Betts, R., Fahey, D. W., Haywood, J., Lean, J., Lowe, D. C., Myhre, G., Nganga, J., Prinn, R., Raga, G., Schulz, M., and Van Dorland, R.: Changes in Atmospheric Constituents and in Radiative Forcing. In: Climate Change 2007: The Physical Science Basis. Contribution of Working Group I to the Fourth Assessment Report of the Intergovernmental Panel on Climate Change, edited by: Solomon, S., Qin, D., Manning, M., Chen, Z., Marquis, M., Averyt, K. B., Tignor, M., and Miller, H. L., Cambridge University Press, Cambridge, UK and New York, NY, USA, 153-160, 2007. 
Franck, U., Odeh, S., Wiedensohler, A., Wehner, B., and Herbarth, O.: The effect of particle size on cardiovascular disorders - The smaller the worse, Sci. Total Environ., 409, 4217-4221, 2011.

Gerasopoulos, E., Kouvarakis, G., Babasakalis, P., Vrekoussis, M., Putaud, J. P., and Mihalopoulos, N.: Origin and Variability of particulate matter $\left(\mathrm{PM}_{10}\right)$ mass concentrations over the Eastern Mediterranean, Atmos. Environ., 40, 4679-4690, 2006.

Ginoux, P., Prospero, J. M., Gill, T. E., Hsu, N. C., and Zhao, M.: Global-scale attribution of anthropogenic and natural dust sources and their emission rates based on MODIS Deep Blue aerosol products, Rev. Geophys., 50, RG3005, doi:10.1029/2012RG000388, 2012.

Jöckel, P., Tost, H., Pozzer, A., Brühl, C., Buchholz, J., Ganzeveld, L., Hoor, P., Kerkweg, A, Lawrence, M. G., Sander, R., Steil, B., Stiller, G., Tanarhte, M., Taraborelli, D., van Aardenne, J., and Lelieveld, J.: The atmospheric chemistry general circulation model ECHAM5/MESSy: Consistent simulation of ozone from the surface to the mesosphere, Atmos. Chem. Phys., 6, 50675104, doi:10.5194/acp-6-5067-2006, 2006.

Kallos, G., Astitha, M., Katsafados, P., and Spyrou, C.: Long-Range transport of anthropogenically and naturally produced particulate matter in the Mediterranean and north Atlantic: current state of knowledge, J. Appl. Meteorol. Climatol., 46, 1230-1251, 2007.

Karanasiou, A., Moreno, N., Moreno, T., Viana, M., de Leeuv, F., and Querol, X.: Health effects from Saharan dust particles, ETC/ACM Technical Paper 2011/4, 2012.

Kojima, T., Buseck, P. R., Iwasaka, Y., Matsuki, A., and Trochkine, D.: Sulfate-coated dust particles in the free troposphere over Japan, Atmos. Res., 82, 698-708, 2006.

Krewski, D., Burnett, R. T., Goldberg, M. S., Hoover, K., Siemiatycki, J., Abrahamowicz, M., and White, W. H.: Part I: Replication and Validation. In: Reanalysis of the Harvard Six Cities Study and the American Cancer Society Study of Particulate Air Pollution and Mortality. A Special Report of the Institute's Particle Epidemiology Reanalysis Project, Health Effects Institute, Cambridge, MA, 2000a.

Krewski, D., Burnett, R. T., Goldberg, M. S., Hoover, K., Siemiatycki, J., Jerrett, M., Abrahamowicz, M., and White, W. H.: Part II. Sensitivity Analysis. In: Reanalysis of the Harvard Six Cities Study and the American Cancer Society Study of Particulate Air Pollution and Mortality. A Special Report of the Institute's Particle Epidemiology Reanalysis Project, Health Effects Institute, Cambridge, MA, 2000b.

Krewski, D., Jerrett, M., Burnett, R. T., Ma, R., Hughes, E., Shi, Y., Turner, M. C., Pope III, C. A., Thurston, G., Calle, E. E., and Thun, M. J.: Extended follow-up and spatial analysis of the American Cancer Society Study linking particulate air pollution and mortality, Health Effects Institute, Boston, MA, 2009.

Lee, J. T., Son, J. Y., and Cho, Y. S.: A comparison of mortality related to urban air particles between periods with Asian dust days and without Asian dust days in Seoul, Korea, 2000-2004, Environ. Res., 105, 409-413, 2007.

Lelieveld, J., Barlas, C., Giannadaki, D., and Pozzer, A.: Model calculated global, regional and megacity premature mortality due to air pollution, Atmos. Chem. Phys., 13, 7023-7037, doi:10.5194/acp-13-7023-2013, 2013.

Lepeule, J., Laden, F., Dockery, D., and Schwartz, J.: Chronic exposure to fine particles and mortality: An extended follow-up of the Harvard Six Cities Study from 1974-2009, Environ. Health Perspect., 120, 965-970, 2012.

Lim, S. S., Vos, T., Flaxman, A. D., Danaei, G., and Shibuya, K.: A comparative risk assessment of burden of disease and injury attributable to 67 risk factors and risk factor clusters in 21 regions, 1990-2010: a systematic analysis for the Global Burden of Disease Study 2010, Lancet, 380, 2224-2260, 2012.

Ma, J., Chen, Y., Wang, W., Yan, P., Liu, H., Yang, S., Hu, Z., and Lelieveld, J.: Strong air pollution causes widespread haze-clouds over China, J. Geophys. Res., 115, D18204, doi:10.1029/2009JD013065, 2010.

Mahowald, N. M., Kloster, S., Engelstaedter, S., Moore, J. K., Mukhopadhyay, S., McConnell, J. R., Albani, S., Doney, S. C., Bhattacharya, A., Curran, M. A. J., Flanner, M. G., Hoffman, F. M., Lawrence, D. M., Lindsay, K., Mayewski, P. A., Neff, J., Rothenberg, D., Thomas, E., Thornton, P. E., and Zender, C. S.: Observed 20th century desert dust variability: impact on climate and biogeochemistry, Atmos. Chem. Phys., 10, 10875-10893, doi:10.5194/acp-10-10875-2010, 2010.

Mallone, S., Stafoggia, M., Faustini, A., Gobbi, G. P., Marconi, A., and Forastiere, F.: Effect of Saharan dust on the association between particulate matter and daily mortality in Rome, Italy, Environ. Health Perspect., 119, 1409-1414, 2011.

Nastos, P. T., Kampanis, N. A., Giaouzaki, K. N., and Matzarakis, A.: Environmental impacts on human health during a Saharan episode at Crete island - Greece, Meteorol. Zeitschr., 20, 517 529,2011

Neophytou, A., Yiallouros, P., Coull, B., Kleanthous, S., Pavlou, P., Pashiardis, S., Dockery, D., Koutrakis, P., Laden, F.: Particulate matter concentrations during desert dust outbreaks and daily mortality in Nicosia, Cyprus, J. Exp. Sci. Environ. Epidemiol., 23, 275-280, 2013.

Ostro, B.: Outdoor air pollution: assessing the environmental burden of disease at national and local levels, World Health Organization (WHO) Environmental Burden of Disease Series No. 5 , 2004.

Perez, L., Tobias, A., Querol, X., Künzli, N., Pey, J., Alastuey, A., Viana, M., Valero, N., González-Cabré, M., and Sunyer, J.: Coarse particles from Saharan dust and daily mortality, Epidemiology, 19, 800-807, 2008.

Polymenakou, P. N., Mandalakis, M., Tselepides, A., and Stephanou, E. G.: Particle size distribution of airborne microorganisms and pathogens during an intensive African Event in the Eastern Mediterranean, Environ. Health Perspect., 116, 292-296, 2008.

Pope III, C. A., Burnett, R. T., Thun, M. J., Calle, E. E., Krewski, Ito, K., and Thurston, G. D.: Lung cancer, cardiopulmonary mortality, and long-term exposure to fine particulate air pollution, JAMA, 287, 1132-1141, 2002.

Pope III, C. A., Burnett, R. T., Thurston, G. D., Thun, M. J., Calle, E. E., Krewski, D., and Godleski, J. J.: Cardiovascular mortality and long-term exposure to particulate air pollution: Epidemiological evidence of general pathophysiological pathways of disease, Circulation, J. Am. Heart Assoc., 109, 71-77, 2004.

Pope III, C. A., Ezzati, M., and Dockery, D. W.: Fine-particulate air pollution and life expectancy in the United States, N. Engl. J. Med., 360, 376-386, 2009.

Pope III, C.A., Burnett, R. T., Turner, M. C., Cohen, A., Krewski, D., Jerrett, M., Gapstur, S. M., and Thun, M. J.: Lung cancer 
and cardiovascular disease mortality associated with ambient air pollution and cigarette smoke: Shape of the exposure-response relationships, Environ. Health Perspect., 119, 1616-1621, 2011.

Pozzer, A., Zimmermann, P., Doering, U. M., van Aardenne, J., Tost, H., Dentener, F. Janssens-Maenhout, G., and Lelieveld, J.: Effects of business-as-usual anthropogenic emissions on air quality, Atmos. Chem. Phys., 12, 6915-6937, doi:10.5194/acp-126915-2012, 2012a.

Pozzer, A., de Meij, A., Pringle, K. J., Tost, H., Doering, U. M., van Aardenne, J., and Lelieveld, J.: Distributions and regional budgets of aerosols and their precursors simulated with the EMAC chemistry-climate model, Atmos. Chem. Phys., 12, 961-987, doi:10.5194/acp-12-961-2012, 2012b.

Pringle, K. J., Tost, H., Metzger, S., Steil, B., Giannadaki, D., Nenes, A., Fountoukis, C., Stier P., Vignati, E., and Lelieveld, J.: Description and evaluation of GMXe: A new aerosol submodel for global simulations (v1), Geosci. Model Dev., 3, 391-412, doi:10.5194/gmd-3-391-2010, 2010.

Sajani, S. Z., Miglio, R., Bonasoni, P., Cristofanelli, P., Marinoni, A., Sartini, C., Goldoni, C. A., De Girolamo, G., and Lauriola, P.: Saharan dust and daily mortality in Emilia-Romagna (Italy), Occup. Environ. Med., 68, 446-451, 2011.

Samet, J. M., Dominici, F., Curriero, F. C., Coursac, I., and Seger, S. L.: Fine particulate air pollution and mortality in 20 U.S. cities, 1987-1994, New Eng. J. Med., 343, 1742-1749, 2000.

Solomon, P. A., Wexler, A. S., and Sioutas, C.: Special issue of Atmospheric Environment for air pollution and health: Bridging the gap from sources-to-health outcomes, Atmos. Environ., 45, 7537-7539, 2011.

United Nations Department of Economic and Social Affairs (UNDES), Population Division: World Population Prospects: the 2010 Revision, (Population data files of the UNDES. We accessed the 28 June 2011 update in November 2012, available at: http://esa.un.org/unpd/wpp), 2011.
Van Donkelaar, A., Martin, R. V., Brauer, M., Kahn, R., Levy, R., Verduzco, C., and Villeneuve, P. J.: Global estimates of ambient fine particulate matter concentrations from satellite-based aerosol optical depth: Development and application, Environ. Health Perspec., 118, 847-885, 2010.

WHO (World Health Organization): The world health report, http: //www.ctc-health.org.cn/file/whr03_en.pdf, 2003.

WHO (World Health Organization): Health Aspects of Air Pollution, http://www.euro.who.int/_data/assets/pdf_file/0003/ 74730/E83080.pdf, 2004.

WHO (World Health Organization): Air quality guidelines, http://www.euro.who.int/_data/assets/pdf_file/0005/78638/ E90038.pdf, Global update 2005.

WHO (World Health Organization): The global burden of disease: 2004 update, Health Statistics and Health Information Systems (WHOSIS), Geneva 2008. (Mortality data files of the WHO regional burden of disease estimates for available at: http://www.who.int/healthinfo/global_burden_disease/ estimates_regional/en/index.html (last access: January 2013), 2004.

WHO (World Health Organization): World Health Organization, Health Statistics and Health Information Systems (WHOSIS), Geneva, 2012. (Data files of the WHO Mortality Database, available at: http://www.who.int/healthinfo/statistics/mortality_ rawdata/en/index.html (last access: November 2012), 2012. 